\title{
Original article \\ Using an accelerometer for analyzing a reach-to-grasp movement after stroke
}

\author{
Stella Maris Michaelsen \\ Raquel Pinheiro Gomes \\ Aline Perão Marques \\ Letícia Cardoso Rodrigues \\ Noé Gomes Borges Junior \\ Renato Claudino \\ Márcio José dos Santos \\ State University of Santa Catarina, Brazil
}

\begin{abstract}
The purpose of this study was using an accelerometer to access the kinematics of reach-to-grasp movements in subjects with hemiparesis. Eight subjects (59.4 \pm 6.9 years old) with chronic hemiparesis $(50.9 \pm 25.8$ months post-stroke) participated in this study. Kinematic assessment was performed using a triaxial accelerometer (EMG Systems, Brazil) attached to the subjects' forearm. Ten reach-to-grasp movements of grabbing a 500ml-size bottle were performed by the subjects with the paretic and the non-paretic upper limbs (ULs). The following spacetemporal variables were calculated and used to compare the paretic and non-paretic ULs: movement time (MT), time to reach the peak velocity, absolute and relative (TPV and TPV\%MT), relative deceleration duration (DEC\%MT), time to peak acceleration (TPA) and peak hand acceleration (PA). Movements were slower in the paretic UL with increased MT, TPA and DEC. The accelerometer allowed to identify of changes in reaching-to-grasp movements of subjects with hemiparesis. When complex systems are not available, accelerometers can be an alternative to measure UL movements.
\end{abstract}

Keywords: kinematic, movement, upper limb, hemiparesis

Resumo- “Usando um acelerômetro para analisar o movimento de alcance e e preensão após o AVE.” O objetivo deste estudo foi usar um acelerometro para avaliar a cinemática do movimento de alcance e preensão de indivíduos com hemiparesia. Participaram deste estudo oito indivíduos $(59,4 \pm 6,9$ anos $)$ com hemiparesia crônica $(50,9 \pm 25,8$ meses pós-AVE). A avaliação cinemática foi realizada através de acelerômetro triaxial (EMG Systems do Brasil) fixado no antebraço. Os indivíduos realizaram 10 movimentos de alcançar uma garrafa de 500 ml pelo membro superior (MS) parético e não parético. As seguintes variáveis espaço-temporais foram calculadas e utilizadas para comparar o MS parético e não parético: tempo de movimento (TM), tempo para alcançar o pico de velocidade, absoluto e relativo (TPV e TPV\%TM), duração relativa da desaceleração(DEC\%TM), tempo para alcançar o pico de aceleração (TPA) e pico de aceleração da mão (PA). Os movimentos foram mais lentos no MS parético com maiores TM, TPA e DEC. A utilização do acelerômetro permitiu identificar alterações no movimento de alcance em indivíduos com hemiparesia. Quando sistemas mais compexos não são disponiveis, acelerometros podem ser uma alternativa para medir o movimento do MS.

Palavras-chaves: cinemática, movimento, membro superior, hemiparesia

Resumen - "El uso de un acelerómetro para analizar un movimiento de alcance i e preensão después del accidente cerebrovascular." El objetivo de este estudio fue analizar por acelerometría, la cinemática del movimento de alcance de los sujetos con hemiparesia. Participaron ocho individuos (59,4 $\pm 6,9$ años) con hemiparesia crónica (50,9 \pm 25,8 meses después del accidente cerebrovascular). La evaluación cinemática se realizó utilizando el acelerómetro triaxial (EMG Systems, Brasil) fijado en el antebrazo. Los sujetos realizaron 10 movimientos para alcanzar una botella de $500 \mathrm{ml}$ por el miembro superior (MS) parético y no parético. Las siguientes variables espacio-temporales fueron calculadas para comparar el MS parético y no parético: tiempo de movimiento (TM), tiempo para alcanzar el pico de velocidad, absoluto y relativo (TPV e TPV\%TM), duración relativa de la desaceleración (DEC\% TM), tiempo para alcanzar el pico de aceleración (TPA) y el pico de aceleración (PA). Los movimientos fueron más lentos en el MS parético con mayor TM, TPA y DEC. La utilización del acelerómetro permitió identificar las alteraciones en el movimiento de alcance en personas con hemiparesia. Cuando complexos sistemas no son disponibles, acelerómetros poden ser una alternativa para medir el movimiento do MS.

Palabras claves: cinemática, movimiento, miembro superior, hemiparesia 


\section{Introduction}

Stroke is a disabling condition that largely affects the individual's activities of daily life (ADLs) performance (Dobkin, 1997). Loss of the arm function is one of the most incapacitating conditions that affect individuals that suffered a stroke. Despite a certain degree of post-lesion motor recovery, many individuals still remain with motor impairment. The altered upper limb (UL) control and coordination prevent effective voluntary movements limiting the level of activity as well as restricting social life and life quality. (Broeks et al., 1999; Nichols-Larsen et al., 2005, Faria-Fortini et al. 2012). Only 5-20\% of patients with initial severe impairment of the UL present fully functional recovery six months post-stroke (Heller et al., 1987; Sunderland et al., 1989). Furthermore, one study showed that one-third of subjects with poststroke hemiparesis were unable to move their UL in the first 12 months, and $36 \%$ remained in the same condition in two years (Wade et al., 1983). In two to four years post lesion, although the fact that partial movement recovery occurs, $50-70 \%$ of patients report loss of UL function (Hunter \& Crome, 2002).

Reaching and grasping movements of individuals with post-stroke hemiparesis are performed in a segmented manner due to a series of factors, e.g., weak muscles, abnormal muscle tone, atypical posture adjustment, abnormal movement synergies, loss of mobility between scapular and shoulder girdle, disrupted muscle activation time and deficient inter joint coordination during voluntary movements (Cirstea \& Levin, 2000; Levin et al., 1996). When the velocity curve of reaching movements was evaluated in these subjects, it showed decrease in movement velocity, trajectory linearity and loss of smoothness (Michaelsen et al., 2001).

Researchers have been for a long time looking for ecologically valid measurements to address UL performance. However, most studies that address UL kinematic assessment of individuals with post-stroke hemiparesis applied data obtained from three dimensional (3D) analysis systems which requires an expensive complex system of cameras. In addition, data processing and analysis are time consuming. Aside using 3D analysis, some studies analyzed movements performed in isolated articulations, such as elbow (Mirbagheri et al., 2008 ) or movements without interaction with objects (Wagner et al., 2007), which may not represent real-word conditions. In order to evaluate the performance of individuals with impaired UL function it is necessary to relate kinematic analyses to tasks performed in ADLs, as UL movements depends on the purpose of the task as well as on the form, orientation and position of the target-object (Trombly \& Wu, 1999). Another approach to carrying out the kinematic assessment of UL is using accelerometers, which are a low-cost procedure that enables the detailed quantitative assessment of the UL movement in different environments (Subramanian et al., 2010). This approach not require complex analysis systems. Furthermore, studies show that the accelerometer reflects accurately the motor characteristics of the paretic UL in daily activities (Calautti et. al., 2005; Green 2007; Niet et.al. 2007; Uswatte et al., 2005; Uswatte et al., 2006).

Therefore, the objective of this study was to assess the using of one accelerometer to identify the differences between movements in paretic versus non-paretic UL when subjects with hemiparesis reaching to grasp an object.

\section{Method}

\section{Subjects}

Eight subjects $(59.4 \pm 6.9$ years old $)$ with chronic hemiparesis $(4.2 \pm 2.1$ years post-stroke) were assessed. Inclusion criteria was subjects with stroke for at least six months; the UL recovery above 30/66points according to the Fugl-Meyer scale; spasticity scored $\leq 2$ in modified Ashworth scale in assessed muscle groups; ability of performing a simple reach-to-grasp task (reaching for and grasp a cylindrical object using the whole hand). Subjects with other associated neurological conditions (such as Parkinson Disease), orthopedic problems on the arm that could interfere with reach-to-grasp task, aphasia or difficulty in understanding the proposed task were excluded. This relatively small sample of subjects were recruited because the goal of the study was assess the utility of the accelerometer in detect differences between paretic and nonparetic UL. Participants were recruited from university extension projects, physiotherapy clinic at Cefid/UDESC and health centers in Florianópolis. Ethical approval was obtained by the University Ethics Board (protocol number 44-2010). Written informed consent was obtained from all participants.

\section{Data collection}

Initially, an identification form was filled out with personal details of the subjects and their anthropometric measurements. Motor assessment data was obtained from: 1) modified Ashworth scale to verify the degree of spasticity from 0 to 4 , where " 0 " no increase in muscle tone and " 4 " affected part(s) rigid in flexion or extension (Bohannon \& Smith, 1987). The following muscles were tested for spasticity in the seated position in order to facilitate data collection: shoulder horizontal adductors, elbow, wrist and fingers flexors; 2) Fugl-Meyer Scale - UL section, used to measure post-stroke motor recovery. This section comprised a cumulative scoring system with 66 points in total. Individual score varies from 0 (does not perform the movement) to 2 (fully performs). Scores between 50 and 65 points reflect mild impairment; 30-49 moderate impairment; and values below 30 points show severe UL impairment (Michaelsen et al., 2011). The clinical evaluation was carried out by a trained physiotherapist after the kinematic assessment using the EMG System triaxial accelerometer (São Jose dos Campos, Brazil). 

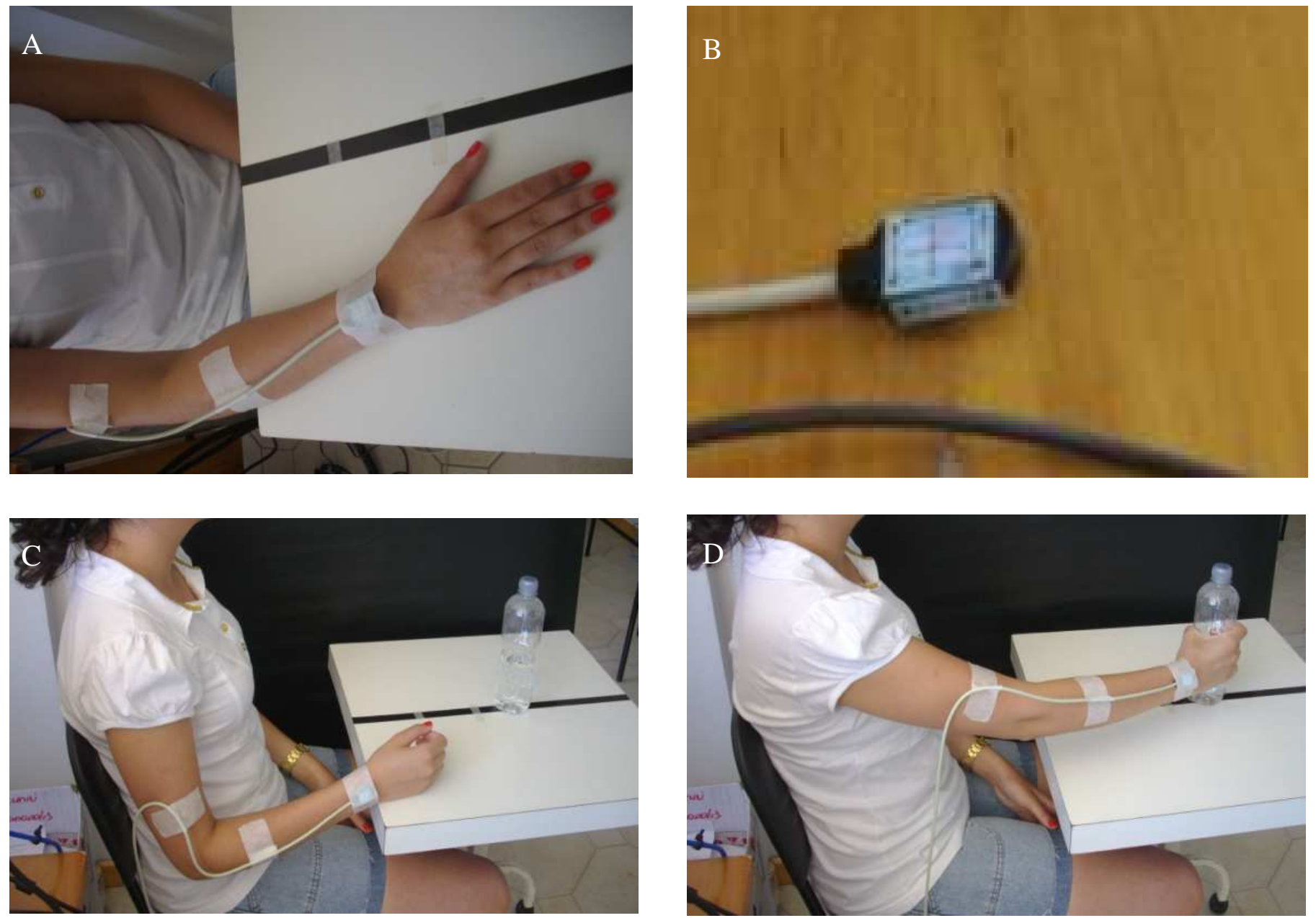

Figure 1. Accelerometer fixation (A); accelerometer (B); analyzed task - reaching and grasping a bottle (C and D): initial position (C) end position (D).

The height of the table was adjusted in such way that subjects were able to rest their arm comfortably, having elbows flexed at $90^{\circ}$ with the forearm and index finger aligned with the table's upper edge. People with hemiparesis tended to use excessive trunk movement in reach-to-grasp tasks (Michaelsen et al 2004), however because the goal was assess "natural" movements, data was collected with the trunk free (Michaelsen et al 2009).

The triaxial accelerometer (EMG system-Brazil) used in this study $(0.7 \mathrm{~cm}$ height $X 2 \mathrm{~cm}$ length $X 1.6 \mathrm{~cm}$ width, weight approximately 25 grams) was securely taped at the dorsal face of the forearm, between the styloid process of the ulna and radius (Figure 1A and 1B). The movement was to reach for and to grasp a $500 \mathrm{ml}$ bottle (height: $20 \mathrm{~cm}$, diameter: $6 \mathrm{~cm}$, containing $200 \mathrm{ml}$ of water) using a cylindrical grasp (Figure 1C and 1D). The bottle was placed at the midpoint aligned of the subject's trunk, at a distance (based on the arm length) where subjects was able to reach and grasp the bottle with their non-paretic UL without moving the trunk. The task was performed at a comfortable speed ("as natural as possible") and repeated 10 trials, first with the non-paretic, and then the paretic upper limb. The tasks was no constrained in accuracy or velocity to better identify differences related to the motor impairment instead eventual differences related to the UL dominance. The average of ten trials for each UL for each participant was calculated and used for statistical analysis. Data was collected at $100 \mathrm{~Hz}$.

\section{Data processing and analysis}

Data was filtered with a $50 \mathrm{~Hz}$ Butterworth low-order filter. The acceleration curve was used to assess the following variables: 1) movement time (MT), determined between the beginning of acceleration and the end of deceleration, until the curve back to zero; 2) absolute time to peak velocity (TPV), defined as the time between the start of movement, i.e., velocity different from zero, and the time of peak velocity that was identified via the acceleration curve when it crossed 
the zero line for the first time and the sign of acceleration changed from positive (acceleration) to negative (deceleration) ; 3) relative time to peak velocity (TPV\%MT) as the percent time when occur the velocity peak in relation to total movement time; 4) relative deceleration duration (DEC\%MT) determined at the start of acceleration reverse (the point where acceleration crosses zero for the first time) up to the end of moment when it returns to zero, shown relative to the MT; 5) peak acceleration (PA), defined as maximum value acceleration point after the movement starts; 6) time to peak acceleration (TPA)- time to achieve the maximum acceleration, i.e., highest point of the curve. These variables were identified and calculated using Matlab ${ }^{\circledR}$ software (version 7.12.0.635 (R2011a), Mathwork Inc, Natick, EUA).

\section{Statistical analysis}

Data normality was tested using the Shapiro-Wilk test and the homogeneity of variance was tested by Levene's statistic. Spatial and temporal parameters between paretic and non-paretic upper limbs were compared by non-paired Student $t$ Test or Mann-Whitney U-test when indicated. The effect sizes were calculated to determine the magnitude of the differences between the means. The differences between the two mean values are presented in units of their SD, expressed as Cohen's $d$. Effect sizes of 0.2-0.5 are considered small; of 0.5-0.8, as medium; and above 0.8 , large. The significance level adopted was $p<0.05$. Data was analyzed using SPSS $®$ 17.0 Software.

\section{Results}

\section{Participants}

All subjects had moderate UL impairment, i. e., FuglMeyer-UL between 30 and 49 points (Table 1).

Table 1. Participants characteristics, anthropometric data, measures for kinematic evaluation and results of clinical evaluation.

\begin{tabular}{ll}
\hline & Mean/standard deviation \\
\hline Sex $(\mathrm{M} / \mathrm{F})$ & $4 \mathrm{M} / 4 \mathrm{~F}$ \\
Type of stroke (I/H) & $6 \mathrm{I} / 1 \mathrm{H}$ \\
Paretic side (R/L) & $1 \mathrm{R} / 7 \mathrm{~L}$ \\
Dominant side (R/L) & $8 \mathrm{R} / 0 \mathrm{~L}$ \\
Arm lenght (cm) & $45.4(3.1)$ \\
Distance to object (cm) & $20,6(3,4)$ \\
Table height (cm) & $70.4(2.4)$ \\
Ahsworth modified scale & \\
shoulder & $1.0(0.5)$ \\
elbow & $1.6(0.4)$ \\
wrist & $1.4(0.2)$ \\
FMS-UL & $39(7.6)$ \\
\hline M=male; F=female; I=isquemic; H=hemorrhagic; R=rigth; L= left; \\
FMS=Fugl-Meyer Scale; UL=upper limb.
\end{tabular}

\section{Comparison between paretic and non-paretic upper limbs using the accelerometer}

One example of raw data obtained by the accelerometer for one trial in one participant is showed in Figure 2. Movements were slower for paretic compared with nonparetic ULs ( $p=0.003$; Figure 3A). Furthermore, TPA was lower for paretic than for non-paretic ( $p=0.01$; Figure $3 \mathrm{~B}$ ) UL and relative deceleration duration was greater for paretic

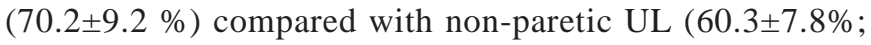
$p=0.04)$. Acceleration peak in paretic and non-paretic ULs were respectively $0.45 \pm 0.44$ and $0.71 \pm 0.72 \mathrm{~m} / \mathrm{s} 2$, without significant differences between sides.

Relative time to peak velocity for paretic compared with non-paretic UL occured respectively at $29.8 \pm 9.2 \%$ and $39.7 \pm 7.8 \%$ of movement duration.

\section{Discussion}

Findings show that it is possible to analyze some of the relevant components of the kinematics of reaching movements by using one accelerometer placed on the subject's wrist. While data collection with video cameras

\section{A}

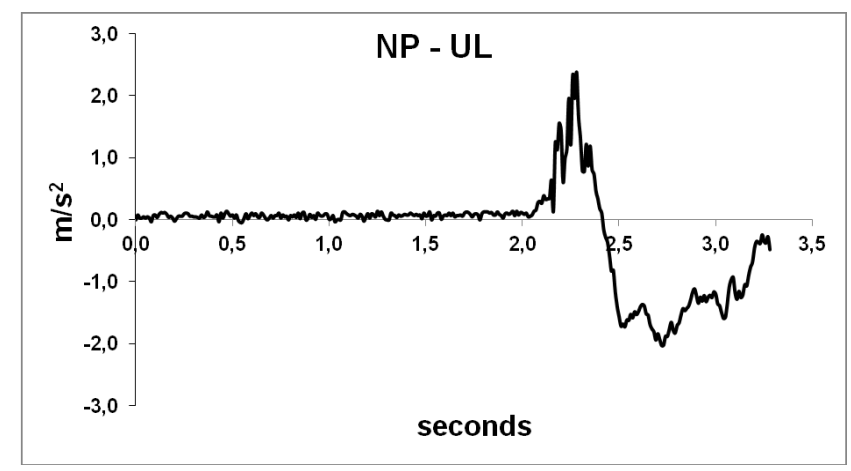

B

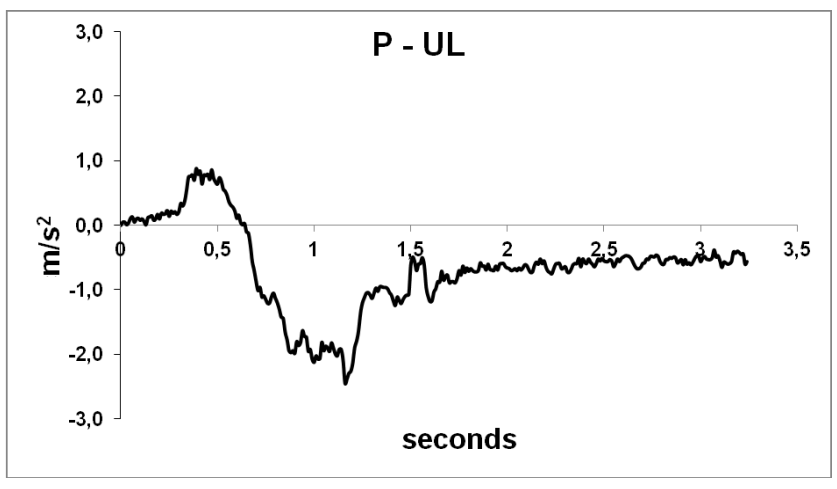

Figure 2. Example of a raw data obtained by the accelerometer for one trial in one participant showing acceleration traces of reach-tograsp for A: non-paretic (NP) and B: paretic (P) upper limb (UL). 

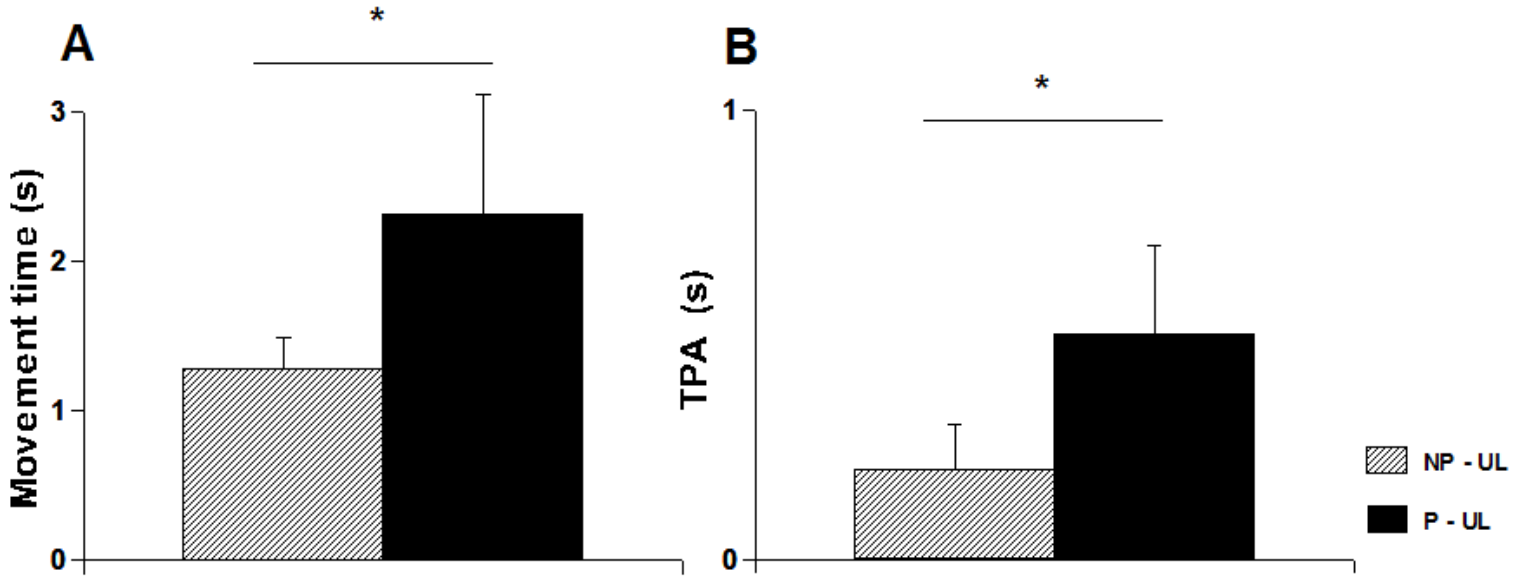

Figure 3. A: Time to reaching movement for paretic (P-UL) and non-paretic upper limb (NP-UL) in subjects with hemiparesis with mild to moderate severity; B:Time to peak acceleration (TPA) in seconds (s) of reaching movement for paretic (P-UL) and non-paretic upper limb (NP-UL) in subjects with hemiparesis of mild to moderate severity, * indicates significant difference $(p<0.05)$.

can be blocked by any obstacle between the camera and the markers, the use of accelerometer is not. Therefore, this instrument can be used in different environments and the data processing and analysis can be simplified. The disadvantage of this procedure is that it is impossible to assess angular components and compensatory movements; however, general data on the spatial and temporal characteristics of reaching-to-grasp movements, i.e., movement time and time to peak velocity showed similar results to those found in literature, where data collection was carried out with video cameras. For example Michaelsen et al. (2009) found that relative TPV in paretic UL was $29 \%$ of the MT when subjects reach to grasp an object with similar characteristics.

Particularly, movement time was prolonged for paretic compared with non-paretic UL. Findings for reaching movements, such as pointing (Cirstea et al., 2003) or yet reach-to-grasp to a cylindrical object show that subjects with hemiparesis are slower than control subjects (Michaelsen et al., 2004). Movement time under this study varied from 1.26 seconds to 3.51 seconds, similar to values found in a study carried out by Magdalon et al. (2008), where the analysis was performed using cameras with reflexive markers in the arm. They observed that movement time to reach for and grasp a bottle with the paretic UL varied between 1.12 and 3.91 seconds. Thus, similar findings were shown in the present study, which suggests that an accelerometer can be useful to assess reaching movements of subjects with hemiparesis. Differences between dominant and non-dominant UL kinematics in healthy individuals are evidenced only when movements are completed in constrained conditions with high level of accuracy or faster speeds (Grosskopf \& Kuhtz-Buschbeck, 2006). Furthermore, without this constraints movement time and peak velocities have been reported as similar between the dominant and non-dominant hands in healthy individuals (Tresilian \& Stelmach 1997; Sainburg \& Kalakanis, 2000). Thus, considering that in the present study the movement assessed did not require great precision and was performed in comfortable velocity for the subject, we do believe that dominance did not affect the pattern of the reach movement of the participants.

Similar as described for time to peak velocity when compared healthy and stroke subjects, the time to peak acceleration was longer for paretic compared with nonparetic UL. Reaching movements performed by healthy individuals is quickly initiated, direct and smooth, while in stroke are slower and less smooth (Michaelsen et al., 2009). Our findings show that the duration of deceleration was greater for paretic compared with non-paretic UL. The $\pm 10 \%$ difference of the duration of deceleration between paretic and non-paretic UL was similar to the difference between paretic UL of subjects with hemiparesis and control subjects reported by Michaelsen et al. (2009), respectively $71 \%$ and $59 \%$ of the MT. This increase in the deceleration phase of reaching tasks shows that subjects with hemiparesis need more time for feedback adjustments than healthy individuals. (van Vliet \& Sheridan, 2007)

Data shows that the greater MT for paretic UL in people with hemiparesis may be related to lower peak velocity values as well as to a longer time required by subjects with hemiparesis in the deceleration phase. These results are in agreement with those carried out by Lang et al. (2006) that showed that stroke patients had deficits in movement peak velocity as well as longer deceleration phase.

The assessment of reaching movements made by the accelerometer enabled the identification of changes commonly found within the reaching movement of subjects with hemiparesis. The identification of time parameters, e.g. absolute time for the peak velocity (identified at the 
acceleration curve), and relative time, enabled the comparison of values found in literature. One limitation of using the accelerometer is that, to facilitate the analysis the initial position of the forearm was controlled to be in neutral supination (i.e similar to the end position when the bottle was grasped - Figure $1 \mathrm{C}$ and D) in the way that the movement occurs predominantly in the axis of the analysis. According to literature, the kinematic assessment of reaching movements can be performed with a video camera; however, when it is not convenient to use this system, such as in a hospital environment, despite some limitations, a simple accelerometer can provide an alternative means of identifying relevant parameters to verify the changes caused by stroke in controlling paretic upper limb movements.

\section{References}

Bohannon, R., \& Smith, M. (1997). Interrater reliability of a modified Ashworth scale of muscle spasticity. Physical Therapy, 67(2), 206-207. Retrieved from: http://ptjournal. apta.org/content/67/2/206.full.pdf

Broeks, J. G., Lankhorst G. J., Rumping K., \& Prevo A. J. (1999). The long-term outcome of arm function after stroke: results of a follow up study. Disability and Rehabilitation, 21(8), 357364. doi: 10.1080/096382899297459.

Calautti C., Jones P. S., Persaud N., Guincestre J.-Y., Naccarato M., Warburton E. A., Baron J.- C. (2006). Quantification of index tapping regularity after stroke with tri-axial accelerometry. Brain Research Bulletin, 70(1), 1-7. Retrieved from: http:// dx.doi.org/10.1016/j.brainresbull.2005.11.001.

Cirstea, M. C., \& Levin, M. F. (2000). Compensatory strategies for reaching in stroke. Brain, 123(pt 5), 940-953. Retrieved from: http://brain.oxfordjournals.org/content/123/5/ 940.full.pdf + html

Cirstea, M.C., Ptito, A., \& Levin, M. F. (2003). Arm reaching improvements with short-term practice depend on the severity of the motor deficit in stroke. Experimental Brain Research, 152(4), 476-488. doi:10.1007/s00221-003-1568-4.

Dobkin, B. H. Impairments, disabilities, and bases for neurological rehabilitation after stroke. Journal of Stroke and Cerebrovascular Diseases, 6(4), 221-226. Retrieved from: http://dx.doi.org/10.1016/S1052-3057(97)80015-8

Green L. B. (2007). Assessment of Habitual Physical Activity and Paretic Arm Mobility Among Stroke Survivors by accelerometry. Topics In Stroke Rehabilitation, 14(6), 9-21. doi: 10.1310/tsr1406-9

Grosskopf, A., Kuhtz-Buschbeck, J.P. (2006). Grasping with the left and right hand: A kinematic study. Experimental Brain Research, 168(1), 230-240. doi: 10.1007/s00221-005-0083-1.

Heller, A., Wade, D. T., Wood, V. A., Sunderland, A., Hewer, R. L., \& Ward, E. (1997). Arm function after stroke: measurement and recovery over the first three months. Journal of Neurology, Neurosurgery, and Psychiatry, 50(6), 714-719. doi:10.1136/ jnnp.50.6.714.

Hunter, S., \& Crome, P. (2002). Hand function and stroke. Reviews in Clinical Gerontology, 12(1), 68-81. doi: http://dx.doi.org/ 10.1017/S0959259802012194.

Kamper, D. G., Mckenna-Cole, A. N. , Kahn, L. E., \& Reinkensmeyer, D. J. (2002). Alterations in reaching after stroke and their relation to movement direction and impairment severity. Archives of Physical Medicine and Rehabilitation,
83(5), 702-707. Retrieved from: http://www.smpp.north western.edu/ smpp_pub/Kamperetal_APMR_2002.pdf

Lang, C. E., Wagner, J. M., Bastian, A. J., Hu, Q., Edwards, D. F., Sahrmann, S. A., \& Dromerick, A. W. (2005). Deficits in grasp versus reach during acute hemiparesis. Experimental Brain Research, 166(1), 126-136. doi: 10.1007/s00221-005-2350-6.

Levin, M. F. (1996). Interjoint coordination during pointing movements is disrupted in spastic hemiparesis. Brain, 119(1), 281 - 293. doi: 10.1093/brain/119.1.281.

Levin, M. F., Michaelsen, S. M., Cirstea, C. M., \& Roby-Brami, A. (2002). Use of the trunk for reaching targets placed within and beyond the reach in adult hemiparesis. Experimental Brain Research, 143(2), 171-180. doi: 10.1007/s00221-001-0976-6.

Magdalon, E. C., Levin, M. F., Quevedo, A.A.F., \& Michaelsen, S. M. (2008). Kinematics of reaching and grasping in a $3 D$ immersive virtual reality environment in patients with hemiparesis. Neurorehabilitation and Neural Repair, 22, 601. ID 299.

Michaelsen, S. M., Luta, A., Roby-Brami, A., \& Levin, M. F. (2001). Effect of Trunk Restraint on the Recovery of Reaching Movements in Hemiparetic Patients. Stroke, 32(8), 1875-1883. doi: 10.1161/01.STR.32.8.1875.

Michaelsen, S. M., Jacobs, S., Roby-Brami, A., \& Levin, M. F. (2004). Compensation for distal impairments of grasping in adults with hemiparesis. Experimental Brain Research, 157(2), 162-173. doi: 10.1007/s00221-004-1829-x.

Michaelsen, S. M., Magdalon, E. C., \& Levin, M.F. (2009). Grip aperture scaling to object size in chronic stroke. Motor Control, 13(2), 197-217. Retrieved from: http://www.ncbi.nlm.nih.gov/ pubmed/19454780

Michaelsen, S. M., Rocha, A. S., Knabben, R. J., Rodrigues, L. P., \& Fernandes, C. G. C. (2011). Tradução, adaptação e confiabilidade interexaminadores do manual de administração da escala de Fugl-Meyer. Revista Brasileira de Fisiterapia, 15(1), 80-88. Retrieved from: http://www.scielo.br/scielo.php? script $=$ sci_arttext\&pid $=$ S1413-35552011000100013

Mirbagheri, M. M., Tsao, C. C., \& Rymer, W.Z. (2008). Changes of elbow kinematics and kinetics during 1 year after stroke. Muscle Nerve, 37(3), 387-95. doi: 10.1002/mus.20965.

Nichols-Larsen, D. S., Clark, P. C., Zeringue, A., Greenspan, A., \& Blanton, S. (2005). Factors influencing stroke survivors' quality of life during subacute recovery. Stroke, 36(7), 1480-1484. doi: 10.1161/001.STR.0000170706.13595.4f.

Niet M, Bussmann J. B., Ribbers G., Stam, H. J. (2007). The Stroke Upper-Limb Activity Monitor: Its Sensitivity to Measure Hemiplegic Upper-Limb Activity During Daily Life. Archives of Physical Medicine and Rehabilitation, 88(9), 11211126. Retrieved from: http://dx.doi.org/10.1016/j.apmr. 2007.06.005.

Sainburg, R. L., Kalakanis, D. (2000). Differences in control of limb dynamics during dominant and nondominant arm reaching. Journal of Neurophysiology, 83(1), 2661-2675. Retrieved from http://jn.physiology.org/content/83/5/2661.full.pdf+html

Subramanian, S. K. Yamanaka, J., Chilingaryan, G. \& Levin, M. F. (2010). Validity of movement quality kinematic variables as measures of arm motor impairment post-stroke. Stroke, 41(10), 2303-2308. doi: 10.1161/STROKEAHA.110.593368.

Sunderland, A., Tinson, D., Bradley, L., \& Hewer, R. L. (1989). Arm function after stroke: an evaluation of grip strength as a measure of recovery and prognostic indicator. Journal of Neurology, Neurosurgery, and Psychiatry, 52(11), 1267-1272. doi:10.1136/jnnp.52.11.1267.

Tresilian J.R., Stelmach G. E. (1997) Common organization for 
unimanual and bimanual reach-to-grasp tasks. Experimental Brain Research, 115(2), 283-299. doi: 10.1007/PL00005697.

Trombly, C. A., \& Wu, C. Y. (1999). Effect of rehabilitation tasks on organization of movement after stroke. The American Journal of Occupational Therapy, 53(4), 333-344. doi: 10.5014/ ajot.53.4.333.

Uswatte, G., Foo, W. L ., Olmstead, H., Lopez, K., Holand, A. \& Simms, L. B. (2005). Ambulatory Monitoring of Arm Movement Using Accelerometry: An Objective Measure of Upper-Extremity Rehabilitation in Persons With Chronic Stroke. Archives of Physical Medicine and Rehabilitation, 86(7), 1498-1501.doi:10.1016/j.apmr.2005.01.010.

Uswatte, G., Giuliani, C., Winstein, C., Zeringue, A., Hobbs, L., $\&$ Wolf, S. L. (2006). Validity of accelerometry for monitoring real-world arm activity in patients with subacute stroke: evidence from the extremity constraint-induced therapy evaluation trial. Archives of Physical Medicine and Rehabilitation, 87(10), 1340-1345. Retrieved from: http://www. sciencedirect.com/science/article/pii/S0003999306005296

Van Kordelaar, J., Van Wegen, E. E. H., Nijland, R. H. M. , Groot, J. H., Meskers, C. G. M., Harlaar, J., \& Kwakkel, G. (2012). Assessing longitudinal change in coordination of the paretic upper limb using on-site 3-dimensional kinematic measurements. Physical Therapy, 92(1), 142-151. doi: 10.2522/ ptj.20100341.

Van Vliet, P. M., \& Sheridan, M. R. (2007). Coordination between Reaching and Grasping in Patients with Hemiparesis and Healthy Subjects. Archives of Physical Medicine and Rehabilitation, 88(10), 1325-1331. doi:10.1016/j.apmr.2007. 06.769

Wade, D. T., Langton-Hewer, R. Wood, V. A., Skilbeck, C. E., \& Ismail, H. M. (1983). The hemiplegic arm after stroke: measurement and recovery. Journal of Neurology, Neurosurgery, and Psychiatry, 46(6), 521-524. doi:10.1136/ jnnp.46.6.521.

Wagner, J. M., Lang, C. E., Sahrmann, S. A., Edwards, D. F., \& Dromerick, A. W. (2007). Sensorimotor impairments and reaching performance in subjects with post-stroke hemiparesis during the first few months of recovery. Physical Therapy, 87(6),751-765. doi: 10.2522/ptj.20060135.

\section{Authors' note}

Stella Maris Michaelsen has a Doctorate degree and is a professor in the Graduate Program of Human Movement Sciences and in the Master's Program of Physiotherapy, State University of Santa Catarina (UDESC), Florianópolis (SC), Brazil

Raquel Pinheiro Gomes, Letícia Cardoso Rodrigues and Renato Claudino have master's degrees from the Graduate Program of Human Movement Sciences, State University of Santa Catarina (UDESC), Florianópolis (SC), Brazil

Aline Perão Marques is a physiotherapist, Center for Health and Sports Sciences (CEFID), State University of Santa Catarina (UDESC), Florianópolis (SC), Brazil

Noé Gomes Borges Junior has a Doctorate degree and is a professor in the Graduate Program of Human Movement Sciences and in the Master's Program of Physiotherapy, State University of Santa Catarina (UDESC), Florianópolis (SC), Brazil

Márcio José dos Santos has a Doctorate degree and is a professor in the
Master's Program of Physiotherapy, State University of Santa Catarina (UDESC), Florianópolis (SC), Brazil

\section{Correspondence to:}

Stella Maris Michaelsen

Address: Rua Pascoal Simone, 358 - CEP 88080-350 Florianópolis SC. Universidade do Estado de Santa Catarina - UDESC - Centro de Ciências da Saúde e do Esporte Telephone: 55 (48) 33218660

E-mail:michaelsenstella@hotmail.com

Manuscript received on January 16, 2013

Manuscript accepted on July 12, 2013

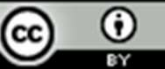

Motriz. Journal of Physical Education. UNESP, Rio Claro, SP, Brazil, eISSN: 1980-6574, is licenced under a Creative Commons License, Version 3.0. 